\title{
PENGARUH SENAM DISMENOREA TERHADAP PENGURANGAN RASA NYERI SAAT MENSTRUASI
}

\author{
Liva Maita
}

Program Studi Kebidanan STIKes Hangtuah Pekanbaru

\author{
ABSTRACT
}

Gymnastics Dysmenorrhea is a relaxation technique that is used to reduce pain during menstruation. This study aims to look at the effect of exercise disminore to reducing pain during menstruation in Prodi DIII Midwifery student STIKes Hang Tuah Pekanbaru 2015. Quasi research type experiment with pretest and posttest study design. Samples taken as many as 30 students who experience dysmenorrhea Data analysis Univariate and Bivariate with Dependent T test. Results of research on the influence of gymnastics disminore get to the reduction of pain during menstruation, with $p$ value 0,000 Value $(p<0.05)$. Disaranaka to the student to be able to learn and practice gymnastics dysmenorrhea every month before menstruation and after menstruation.

Keywords: Gymnastics Disminore, Pain Menstruation

\section{PENDAHULUAN}

Disminore ini adalah kekakuan atau kejang di bagian bawah perut yang terjadi pada waktu menjelang atau selama menstruasi, yang memaksa wanita untuk beristirahat atau berakibat pada menurunnya kinerja dan berkurangnya aktifitas sehari-hari (Lutherer, 2012).

Masalah ini setidaknya mengganggu 50\% wanita masa reproduksi dan $60-85 \%$ pada usia remaja, yang mengakibatkan banyaknya absensi pada sekolah maupun kantor. Pada umumnya $\quad 50-60 \%$ wanita diantaranya memerlukan obat-obatan analgesik untuk mengatasi masalah dismenore ini (Puji 2012).

Keadaan ini yang banyak membuat jumlah absensi di Sekolah meningkat (10\% remaja puteri yang menjadi murid sekolah lanjutan tiap bulan) dan absen pekerjaan (yang diperkirakan mencapai 140 juta jam kerja yang hilang tiap tahun). Insidensi ini mencapai puncak pada wanita pada usia awal 20-an kemudian menurun secara bertahap (Puji, 2012)

Gejala-gejala yang sering terjadi pada wanita mengalami disminore biasanya adalah dengan merasakan nyeri kejang otot spasmodik I di bagian perut bawah dan menyebar ke sisi dalam paha atau bagian pinggang yang menjelang haid atau selama haid akibat kontraksi otot rahim. Keluhan nyeri disminore bisa ringan sampai berat dan berubah ke seluruh tubuh, antara lain: mual, muntah, lelah, sakit pada daerah bawah pinggang, cemas, tegang, pusing dan bingung (Harmanto, 2006).

Berdasarkan penelitian Ramadina (2013) yang dilakukan di SMP Negeri 3 Pekanbaru, dari 92 orang siswi, sebanyak $81,52 \%$ mengalami dismenore dengan tingkat nyeri dismenore yang ringan dan sedang. Dari $62,19 \%$ siswi yang mengalami dismenore mengatakan mengalami kesulitan untuk berkonsentrasi saat belajar serta merasa malas, risih, dan sulit beraktifitas.

Dismenore dapat diatasi dengan terapi farmakologi dan non farmakologi. Terapi nonfarmakologi antara lain, kompres hangat, olahraga, terapi mozart, dan elaksasi. Senam Disemenorea mampu meningkatkan produksi endorphin (pembunuh rasa sakit alami tubuh), dapat meningkatkan kadar serotonin (Shopia, 2010).

Berdarsarkan survey sementara di DIII Kebidanan dari 35 orang yang di wawancarai 23 orang mengalami disminore sehigga mengganggu kegiatan belajar.

\section{METODOLOGI PENELITIAN}

Jenis penelitian yang digunakan yaitu eksperimen semu (Quasi Experimental Designs). Desain penelitian yang digunakan yaitu Pretest Posttest. Dimana subjek penelitian dilakuka dua kali pengukuran nyeri dismenore sebelum dan 
sesudah melakukan senam. Populasi dalam penelitian ini adalah mahasiswa kebidanan STIKes Hangtuah Pekanbaru. Sampel penelitian sebanyak 30 orang mahasiswa yang mengalami dismenorea. Jenis data menggunakan data primer. Analisa data dilakukan secara univariat dan bivariat dengan uji $\mathrm{T}$ dependent.

\section{HASIL DAN PEMBAHASAN}

a. Analisis Univariat

Nilai rata-rata nyeri pada saat sebelum (pretest) dan sesudah (post test) melakukan senam disminore.

Tabel. 1 Distribusi rata-rata Nyeri saat Menstruasi pada Mahasiswi DIII

Kebidanan STIKes Hang Tuah Pekanbaru sebelum dan sesudah senam

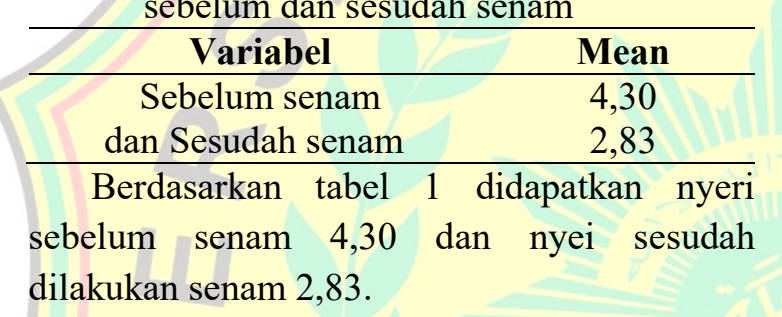

Tabel. 2 Distribusi rata-rata Nyeri Dismenorea pada Mahasiswi DIII Kebidanan STIKes Hang Tuah Pekanbaru sebelum

\begin{tabular}{ccc}
\multicolumn{2}{c}{ senam } \\
\hline \multirow{2}{*}{ Variabel } & \multicolumn{2}{c}{ Nyeri Menstruasi } \\
\cline { 2 - 3 } & $\mathrm{N}$ & $\%$ \\
\hline Tidak nyeri & 0 & 0 \\
Nyeri ringan & 2 & 6,7 \\
Nyeri sedang & 9 & 30 \\
Nyeri Hebat & 15 & 50 \\
Nyeri tak & 4 & 13,3 \\
tertahankan & 30 & 100 \\
Jumlah & 30
\end{tabular}

Dari tabel 2 menunjukkan tingkatan nyeri sebelum senam disminore tingkatan nyeri terbanyak adalah mahasiswi dengan skala nyeri hebat berjumlah 15 mahasiswi $(50 \%)$

Tabel. 3 Distribusi rata-rata Gejala Pennyeri dismenorea saat Menstruasi pada Mahasiswi DIII Kebidanan STIKes Hang

Tuah Pekanbaru Sesudah Melakukan Senam.

\begin{tabular}{|c|c|c|}
\hline \multirow[t]{2}{*}{ Variabel } & \multicolumn{2}{|c|}{ Nyeri Menstruasi } \\
\hline & & $\%$ \\
\hline Tidak nyeri & 3 & 10 \\
\hline Nyeri ringan & 16 & 53,3 \\
\hline Nyeri sedang & 8 & 26,7 \\
\hline Nyeri Hebat & 3 & 10 \\
\hline $\begin{array}{ll}\text { Nyeri tak } \\
\text { tertahankan }\end{array}$ & 0 & 0 \\
\hline Jumlah & 30 & 100 \\
\hline
\end{tabular}

Dari tabel 3 menunjukkan tingkatan nyeri sesudah senam disminore tingkatan nyeri terbanyak adalah mahasiswi dengan skala nyeri ringan berjumlah 16 mahasiswi $(53,3 \%)$

\section{b. Analisis Bivariat}

Tabel. 4 Distribusi Rata-Rata Efektifitas Senam Dismenoea Terhadap Penurunan Nyeri

Disemenorea Responden Sebelum Dan Sesudah Senam Dismenorea

\begin{tabular}{llllll}
\hline Variabel & Mean & SD & SE & $\begin{array}{c}\text { P } \\
\text { Value }\end{array}$ & $\mathbf{N}$ \\
\hline $\begin{array}{c}\text { Nyeri } \\
\text { sebelum }\end{array}$ & 4,30 & 2,806 & 0,512 & 0,001 & 30 \\
$\begin{array}{c}\text { senam } \\
\text { Nyeri }\end{array}$ & 2,83 & 2,805 & 0,512 & & 30 \\
$\begin{array}{c}\text { sesudah } \\
\text { senam }\end{array}$ & & & & & \\
\hline
\end{tabular}

Dari hasil penelitian didapatkan bahwa ratarata nyeri sebelum melakukan senam adalah 4,30, dengan standar deviasi 2,086. Sedangkan nilai rata-rata nyeri sesudah senam adalah 2,83 dengan standar deviasi 2,085. terlihat sedikit perbedaan nilai mean perbedaan antara nyeri sebelum senam dan nyeri sesudah senam adalah 1,47 dengan standar deviasi 0,001 Hasil uji statistik di dapatkan nilai $p=0,001$ maka dapat disimpulkan ada perbedaan yang signifikan antara nyeri dismenorea sebelum melakukan senam dan nyeri dismenorea sesudah melakukan senam.

Hasil penelitian terdapat perbedaan antara nyeri disminore sebelum melakukan senam, dan setelah melakukan senam diperoleh Hasil uji hipotesis ini menggunakan uji T-Test Dependent (Uji Parametrik) didapati nilai $p=0,00(p<0,05)$. Hasil penelitian ini menunjukkan bahwa senam disminore efektif menurunkan skala nyeri pada saat menstruasi.

Disminore ini sendiri dipengaruhi oleh faktor fisik dan psikis seperti stress serta pengaruh hormon prostaglandin. Oleh karena 
itu dengan melakukan senam disminore, tubuh akan menghasilkan hormon $\beta$-endorphin yang berfungsi sebagai penenang alami di dalam tubuh manusia yang diproduksi oleh otak yang dapat mengurangi stress, menghasilkan rasa nyaman serta mengurangi nyeri saat menstruasi (Puji, 2012).

Hasil penelitian ini, didukung oleh hasil penelitian yang dilakukan Sormin (2014), dimana pada penelitian yang dilakukannya dengan kelompok intervensi menggunakan uji $T$ berpasangan $p=0,00(p<0,05)$, sedangkan pada kelompok kontrol menggunakan uji alternatif Wilocxon didapati nilai $p=0,276(p<0,05)$, yang artinya senam disminore berpengaruh terhadap pengurangan rasa nyeri saat menstruasi.

Menurut asumsi peneliti dengan adanya hasil penelitian yang menyatakan bahwa senam disminore dapat menurunkan rasa nyeri saat menstruasi, ternyata terdapat penurunan rasa nyeri 1 sampai 2 skala derajat nyeri, seperti dari skala nyeri paling hebat menjadi nyeri sedang, dan dari nyeri sedang menjadi tidak nyeri sama sekali.

\section{KESIMPULAN}

1. Hasil identifikasi nyeri disminore yang dirasakan pada saat menstruasi sebelum dilakukan senam disminore di dapatkan rata-rata adalah nyeri hebat sebanyak $15(50,0 \%)$ mahasiswi dan sesudah melakukan senam disminore didapatkan rata-rata nyeri disminore adalah nyeri ringan sebanyak 16 $(53,3 \%)$ mahasiwi.

2. Berdasarkan hasil penelitian diperoleh hasil $p=0,000$ lebih kecil dari $p$ Value 0,05 sehingga disimpulkan terdapat pengaruh senam disminore terhadap pengurangan rasa nyeri saat menstruasi.

\section{DAFTAR PUSTAKA}

Lutherer, O.L (2012). Buku Ajar Patofisiologi. Jakarta: Buku Kedokteran EGC

Puji, I.(2012), Efektivitas Senam Dismenore Dalam Mengurangi Dismenore Pada Remaja Putri Di Smu N 5 Semarang. Skripsi, Keperawatan Semarang. Hal (3)

Ramadina, S. (2014), Efektifitas Teknik Relaksasi Genggam Jari Dan Nafas Dalam Terhadap Penurunan Dismenore. Program Studi Ilmu Keperawatan Universitas Riau. Hal (3) Sorman, M.N (2014). Efektivitas Senam Dismenore Dalam Mengurangi Dismenore Pada Remaja Putri Di Smp Negeri 2 Siantan Kabupaten Pontianak. Skripsi, Program Stu idi Keperawatan Fakultas Kedokteran Universitas Tanjungpura Pontia. 